\title{
Anxiolytic effect of olive leaf tea on mice
}

\begin{abstract}
According to current scenarios, the daily lifestyle of majority of the population is full of stress, worry and anxiety. This life style is also imparting its great role in psychological disorders. To improve the mental conditions, along with keeping a healthy life style, it is better to incorporate natural ingredients in diet. Historically, olive leaves have been used for medicinal purposes as well as being considered a symbol of peace. A study was conducted to evaluate the anxiolytic effect of olive leaf tea on mice. Distilled water $0.2 \mathrm{~mL}$ was used as control and administered to 6 mice labeled as Group I whereas Olive leaf tea was prepared freshly with dried olive leaves and administered orally at $0.2 \mathrm{~mL}$ to 6 mice labeled as Group II (treated) for 28 days. To evaluate CNS activity, a number of tests were performed including: Head dip, Cage crossing and Open field test. Upon evaluation of results, marked decrement was seen in number of head dips, cage crossing and also in central and peripheral square crossing. In accordance with the above result, it was concluded that the phenolic compound in olive leaves i.e. Oleuropein possesses some anxiolytic activity, besides its other known various pharmacological activities. Not only can olive leaf tea be prepared freshly at home, it has no known side effects and is economical. Therefore it can bestow a great part in preventing psychological disorder as well as imparting healthy life style.
\end{abstract}

Volume 8 Issue 5 - 2019

\author{
Sana sarfaraz,' Tanveer bano, ${ }^{2}$ Hafsa khalid, ${ }^{2}$ \\ Aimen zafar, ${ }^{2}$ Anoosha atique, ${ }^{2}$ Areesha \\ rashid $^{2}$ \\ 'Department of pharmacology, Faculty of pharmacy, Jinnah \\ University for women Karachi, Pakistan \\ ${ }^{2}$ Faculty of Pharmacy, Jinnah University for Women \\ Karachi-74600 Pakistan
}

Correspondence: Sana sarfaraz, Department of pharmacology, faculty of pharmacy, Jinnah University for women Karachi-74600 Pakistan,Email Sana.sarraz@live.com

Received: September 15, 2019 | Published: October 31, 2019

Keywords: anxiety, cage crossing, head dip, open field, oleuropein, olive leaf.

Abbreviations: ANOVA, analysis of variance; GABA, gamma amino butyric acid; GAD, generalized anxiety disorder; MAOI: mono amino oxidase inhibitors; SSRI, selective serotonin reuptake inhibitors

\section{Introduction}

Anxiety can be defined as the feeling of unease, most often including feelings of apprehension, nervousness, dreadfulness and tension. ${ }^{1}$ As long as the subject is in a state of anxiety, additional feelings are also experienced such as panic, fear, insomnia, besides that other physical symptoms are also observed. ${ }^{2}$ Not only mental health but the overall well-being of an individual gets disturbed due to anxiety. The classic symptoms of anxiety include sleep difficulties, inability to rest, breathing problems, heart palpitations, nervous stomach, headaches, neck tension, and worries, being panicked, frightened, etc. ${ }^{3}$ Bio psychosocial factors interact in situations of fear, trauma or stress which produce clinically significant symptoms of anxiety. Selective mutism, specific phobia, agoraphobia, social phobia, panic disorder, bipolar disorder and generalized anxiety disorder (GAD) are types of anxiety. ${ }^{4}$ Other causes of anxiety are thought to be the dysregulation of neurotransmitters specifically low levels of gamma amino butyric acid (GABA) which is an inhibitory transmitter, and the abnormal neuronal circulation in amygdala that controls fear and sentiments. Both of these mechanisms results in anxiety. Anxiety can be detected on the basis of standardized clinical questionnaires namely Taylor Manifest anxiety scale and Zulf Self-anxiety scale. ${ }^{5-7}$ Currently the common medications employed to treat anxiety are selective serotonin reuptake inhibitors (SSRI), mono-amino oxidase inhibitors (MAOI) etc. ${ }^{8}$
In ancient times, herbs and other natural products were used to relieve various illnesses which are now largely replaced by allopathic medications. The undesirable side effects and physiological dependence are the major problems associated with allopathic drugs, including those used to alleviate anxiety. This has led to the initiation of many researches to find a safe and effective natural resource to treat various ailments. ${ }^{9,10}$ Olive leaf is the leaf from olive tree (Oleaeuorpaea) belongs to the family Oleaceae. The olive tree is thick and short, mostly ranges from shrubs to $10 \mathrm{~m}$ height. The leaves are shortly stalked and ovate, leathery, narrow oblong and attenuate, ranges from $4-10 \mathrm{~cm}$ in length and $1-3 \mathrm{~cm}$ wide. Olive tree is a monoecious plant and is cultivated in different parts of the world including mostly Mediterranean area in Italy, Spain, Portugal, France and Greece. The dried leaves, olive leaf extract and the oil of the olive fruits are used medicinally. Phenolic compounds, flavonoids, flavones, secoiridoids glycosides are present in all parts of the olive tree. Decoction or tea prepared from dried olive leaves is used to treat multiple infections, gastrointestinal illnesses and many more ailments. ${ }^{11}$

Oleuropein is the most important and noticeable phenolic compound present in olive plant. It possesses various pharmacological properties including anti-inflammatory, anti-anxiety anti-oxidant, anti-atherogenic, anticancer, antimicrobial, antiviral, skin protectant, anti-aging, neuro-protective, anti-diabetic, hypotensive, antipyretic and many more. Oleuropein is significantly much more concentrated in olive leaf than in other parts of the tree. ${ }^{12,13}$ This current study is designed to evaluate the effect of olive leaf tea on anxiety by developing anxiety models in mice. 


\section{Materials and method}

\section{Experimental animals}

This study has been carried out on albino mice of either sex weighing $20-24 \mathrm{~g}$ in weight. They were divided into 2 groups each comprising of 6 mice. They were kept in the animal house of Jinnah University for Women. Food and water was provided daily as required, and were kept under the environmental conditions $23 \pm 2{ }^{\circ} \mathrm{C}$. The study was approved by the ethical committee of the institute.

\section{Material}

Fresh olive leaves were picked from olive trees from Kashmir and were allowed to dry in the dark. The leaves were then bought to and identified by Department of Pharmacognosy, Faculty of Pharmacy Jinnah University for Women, Karachi.

\section{Dosing regime}

Group I was taken as the control sample and administered $0.2 \mathrm{~mL}$ distilled water. Group II was taken as test sample and given $0.2 \mathrm{~mL}$ of olive tea orally once a day. Stock solution was prepared by dissolving $35 \mathrm{mg}$ olive tea leaves in $300 \mathrm{~mL}$ of lukewarm, distilled water, ${ }^{14}$ the $0.2 \mathrm{ml}$ dose was calculated after weight adjustment of the mice. The study was carried out for 28 days.

\section{Performance methodology}

\section{Head dip test}

Head dip or whole board test is a method which is useful for identification of anxiety. It consists of an enclosed wooden rectangular box with a hole of $2.5 \mathrm{~cm}$ in diameter and found in all walls. ${ }^{15}$

\section{Procedure}

At the beginning of experiment the mice were familiarized with the wooden box. The temperature was maintained at room temperature. The mice were placed in the center area of the box and allowed to roam freely for 5 minutes. The number of times the mice stuck out its snout from the hole was noted. After performing the experiment, the smell of animal was cleared from the apparatus by cleansing it with $70 \%$ alcohol. ${ }^{16}$

\section{Open field test}

Open field test is used to determine the emotional behavior in rodents. It can also be used to measure exploratory activity, locomotors activity with idea of anxiety related behavior in rodents. ${ }^{17}$ The apparatus consists of a large square chamber, measuring $42 \mathrm{~cm}$ in height. The floor of the periphery is marked into 25 squares of equal length and width within a diameter of $15 \mathrm{~cm}$. A central square of equal size is also present in middle arena.

\section{Procedure}

The mice were held gently by the tail as they were placed into the center of the arena in the open field one at a time. The mice moved in the central and peripheral areas. The number of times that it moved was recorded for 5 minutes. The apparatus was cleaned with $70 \%$ alcohol to remove the odor of subject. ${ }^{18}$

\section{Cage crossing}

Cage crossing is an exploratory and behavioral test for rodents. Anxiety-like behavior is also determined by this method. An increased number shows anxiety-like behavior whereas a reduced number shows anxiolytic behavior. The apparatus consists of a square box that is closed on all ends and is transparent in color. The top consists of holes. The cage should be kept empty to avoid distractions for the rodents.

\section{Procedure}

One mouse at a time is placed in the apparatus and is observed for 5 minutes. After each reading, clean the apparatus with $70 \%$ alcohol to remove or clear off the smell of rodents, ${ }^{18}$ for the analysis of results SPSS tool version 19 was used. First the means of all the tests were taken and then the means were compared with the control value. Oneway ANOVA was applied followed by post hoc Tukey's test. The result was highly significant if $\mathrm{p}$ was $\leq 0.001$.

\section{Results and discussion}

Historically, olive leaves have been used for medicinal purposes and are considered as a symbol of peace. Therefore, it is believed that olive leaf tea imparts a soothing and relaxing effect. Nowadays, olive leaf tea is preferred over black tea and green tea due to presence of zero amount of caffeine. ${ }^{19}$ Initially, when the animals were placed in the apparatus they made attempts to run off due to stressful reaction, ${ }^{20}$ which was further confirmed by the literature survey suggesting high levels of corticosteroids when subjected to experimental conditions. ${ }^{21}$ It can be said that anxiety develops due to dread when exposed to the apparatus, so the reduction in number of head dips can be considered as the reduction in anxiety and fear. Our results showed reduction in head dip from 20 (baseline) to 6 on $28^{\text {th }}$ day of dosing, ${ }^{22}$ this presumption supports our result that olive leaf tea has anxiolytic properties. Oleuropein is the main phenolic component that is responsible for the marked therapeutic effects (Table 1)(Figure 1). ${ }^{11}$

Table I Effect on olive leaf tea on head dip

\begin{tabular}{llcccc}
\hline Solutions & Baseline & $\mathbf{7}$ Days & I4 days & $\mathbf{2 1}$ days & $\mathbf{2 8}$ days \\
\hline Control 0.2mL Distilled water & $18 \pm 1.41$ & $19 \pm 1.04$ & $18 \pm 1.36$ & $19 \pm 1.03$ & $19 \pm 0.81$ \\
Olive Leaf Tea $(0.2 \mathrm{~mL})$ & $20 \pm 1.37$ & $15 \pm 0.75^{* * *}$ & $12 \pm 0.83^{* * *}$ & $9 \pm 0.82^{* * *}$ & $6 \pm 0.79 * * *$ \\
\hline
\end{tabular}

Values are Mean $\pm \mathrm{SD}, \mathrm{N}=6=$ number of animals, ${ }^{* * *} \mathrm{p}<0.00 \mathrm{I}=$ highly significant 


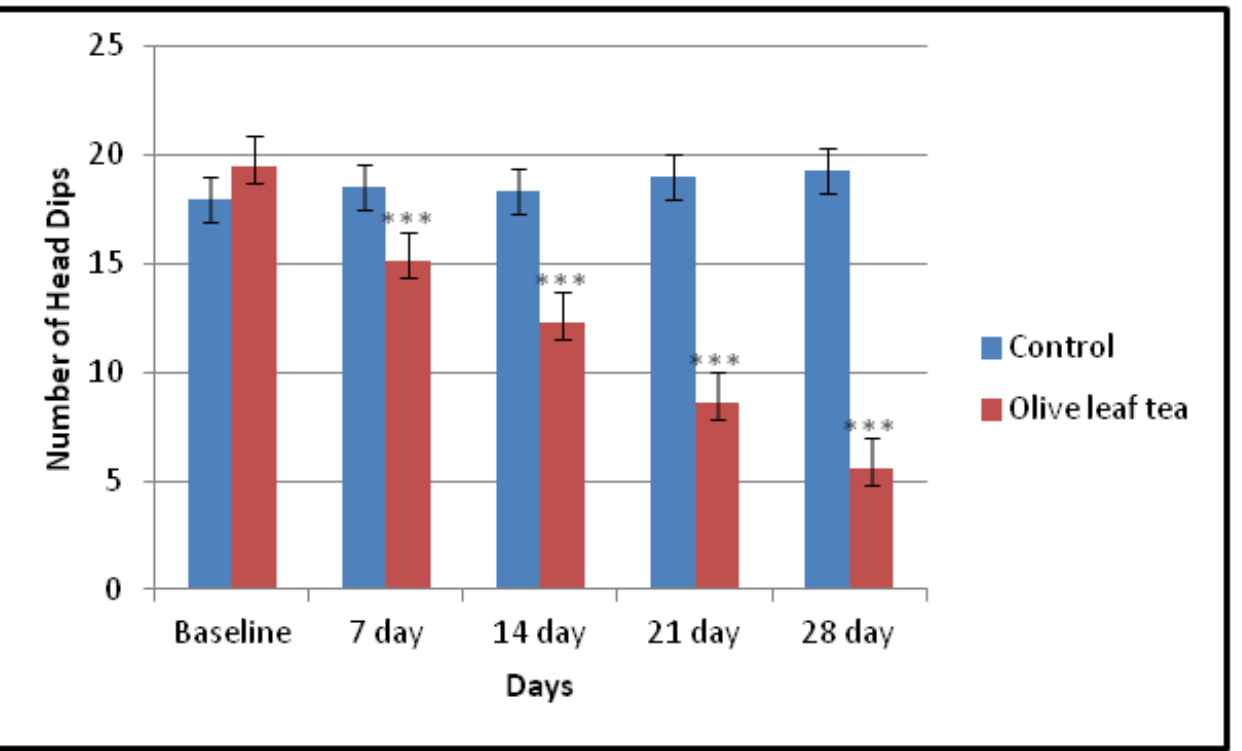

Figure I Effect of olive leaf tea on head dip.

On exposure to cage crossing apparatus, mice crossed the cage numerous times due to the resulting state of fear. Though after administration of Olive leaf tea number of cage crossing decreased significantly. ${ }^{23}$ Olive leaf tea was administered to mice on daily basis, according to Table 2 which showed a marked reduction in the number of cage crossings on day $21^{\text {st }},{ }^{15}$ which were further reduced on day $28^{\text {th }}{ }^{10}$ This showed that anxiety levels of mice were significantly reduced. Anxiety produces stress which causes increase production of adrenal hormones as well as increase in the utilization of vitamin $\mathrm{C}, \mathrm{E}$ and other micronutrients which enhance metabolism of fats, carbohydrates and proteins to produce energy to overcome stress. ${ }^{24}$ Biochemical changes are induced due to stresses which are normally overcome by body's biological anti-oxidant system, including enzymatic anti-oxidants such as glutathione peroxidase and superoxide dismutase etc. Non-enzymatic anti-oxidants such as vitamin $\mathrm{C}, \mathrm{E}$ and trace minerals provide secondary defense. ${ }^{25}$

Table 2 Effect of olive leaf tea on cage crossing

\begin{tabular}{lccccc}
\hline Solutions & Baseline & 7 Days & 14 days & 21 days & 28 days \\
\hline Control 0.2mL Distilled water & $4 I \pm 1.21$ & $4 I \pm 0.63$ & $42 \pm 0.89$ & $41 \pm 0.86$ & $42 \pm 0.90$ \\
Olive Tea $(0.2 \mathrm{~mL})$ & $42 \pm 1.32$ & $34 \pm 0.75^{* * *}$ & $27 \pm\left. 0.8\right|^{* * *}$ & $15 \pm\left. 1.2\right|^{* * *}$ & $10 \pm 0.98^{* * * *}$
\end{tabular}

Values are Mean $\pm S D, N=6=$ number of animals, $* * * p<0.00 I=$ highly significant

Oleuropein possesses potent antioxidant and anti-inflammatory properties. Chelation of metal ions such as $\mathrm{Cu}$ and $\mathrm{Fe}$ with Oleuropein prevents free radical formation. ${ }^{26}$ Furthermore, it inhibits several inflammatory enzymes..$^{27}$ Both Oleuropein and hydroxytyrosol have been shown to be scavengers of superoxide anion, contributing to its anti-oxidant nature (Table 2) (Figure 2). ${ }^{28}$

The open field test was primarily introduced to measure the emotional behavior in rats but it has proven to be equally successful with mice as well. ${ }^{29,30}$ The experiment contributes an exclusive probability to systematically determine new environmental exploration, usual locomotors activity, and contributes in basic screening for anxietyrelated behavior in rodents. ${ }^{31}$ Social isolation and stress due to bright light exposure posed an unfamiliar test environment to the rodents. These two factors had an impact in production of anxiety like behavior in an open field apparatus. ${ }^{32}$
(Table 3) (Figure 3) results showed a significant reduction in the number of peripheral boxes crossed by the test mice as compared to the control mice. Meanwhile, s slight increase in the number of central squares crossed by the test mice was shown. The baseline reading was 3 which were increased to 7 on $28^{\text {th }}$ day of dosing. The increased frequency showed reduced anxiety and augmented exploratory actions. $^{5}$

Oleuropein (OLE) improves various physiological functions, produces multiple pharmacological actions in the central nervous system, and has in vitro and in vivo neuro protective effects. ${ }^{33,34}$ In the literature study on an animal model of anxiety, involving elevated plus maze OLE administration potentially reduced anxiety-like behavior by more entries and exploratory activities, and less open arm avoidance, resulting in reduced index of anxiety (Table 4) (Figure 4). ${ }^{35}$ 


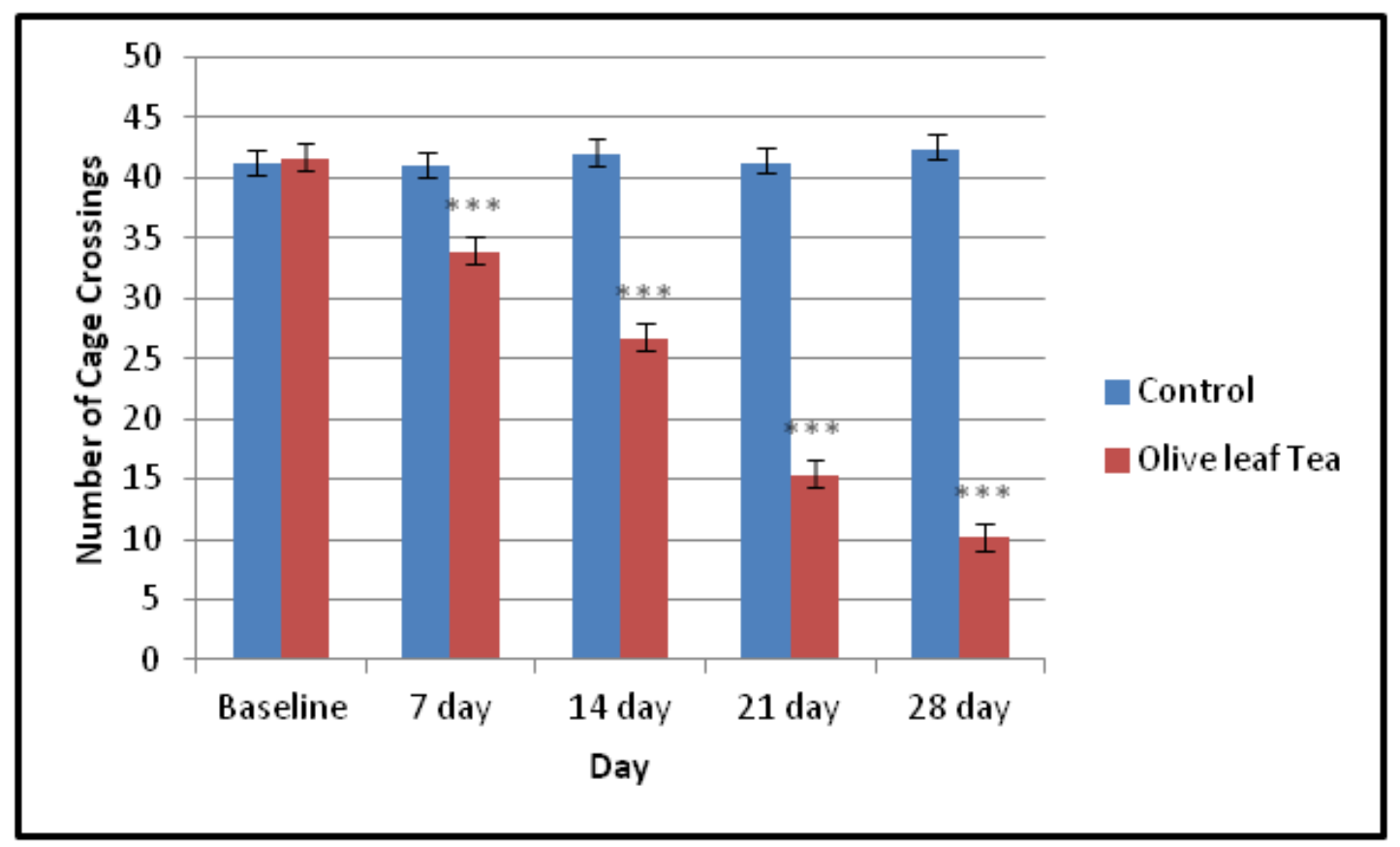

Figure 2 Effect of olive leaf tea on cage crossings.

Table 3 Effect of olive leaf tea on open field test (central crossings)

\begin{tabular}{llllll}
\hline Solutions & Baseline & $\mathbf{7}$ Days & $\mathbf{1 4}$ days & $\mathbf{2 1}$ days & $\mathbf{2 8}$ days \\
\hline Control 0.2mL Distilled water & $3 \pm 0.75$ & $3 \pm 1.09$ & $4 \pm 0.81$ & $3 \pm 1.26$ & $3 \pm 0.74$ \\
Olive Tea $(0.2 \mathrm{~mL})$ & $3 \pm 0.89$ & $5 \pm 0.51^{* * *}$ & $6 \pm 0.54 * * *$ & $6 \pm 0.51 * * *$ & $7 \pm 0.52^{* * *}$ \\
\hline
\end{tabular}

Values are Mean $\pm S D, N=6=$ number of animals, $* * * p<0.00$ I =highly significant

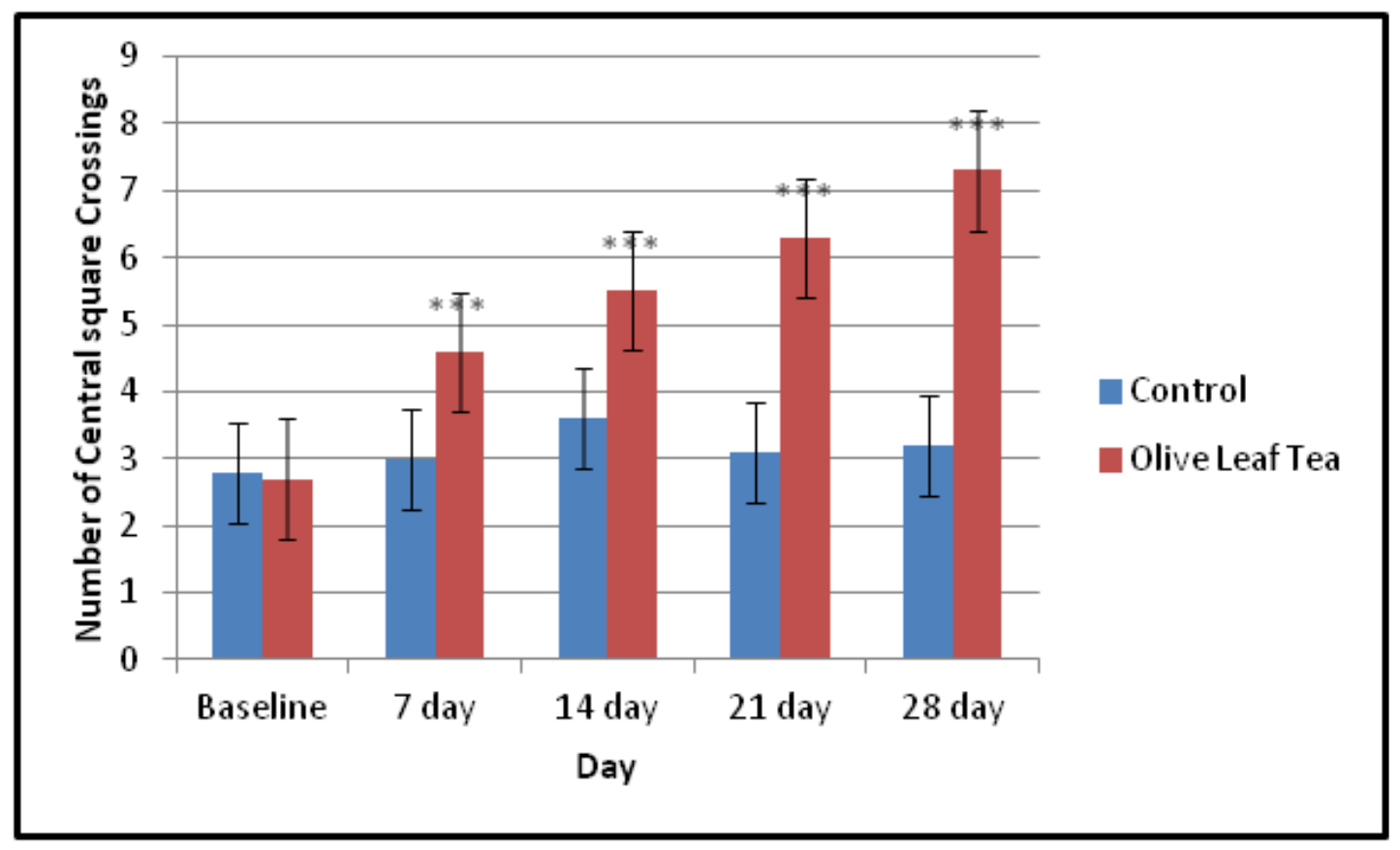

Figure 3 Effect of olive leaf tea on central square crossings. 
Table 4 Effect of olive leaf tea on open field test (peripheral square crossings)

\begin{tabular}{llllll}
\hline Solutions & Baseline & $\mathbf{7}$ Days & I4 days & 2I days & 28 days \\
\hline Control $0.2 \mathrm{~mL}$ Distilled water & $116 \pm 0.8 \mathrm{I}$ & $117 \pm 0.82$ & $116 \pm 1.21$ & $117 \pm 0.75$ & $118 \pm 0.69$ \\
Olive Tea $(0.2 \mathrm{~mL})$ & $117 \pm 1.03$ & $102 \pm 1.16 * * *$ & $86 \pm 1.01 * * *$ & $71 \pm 0.98 * * *$ & $56 \pm 0.79 * * *$ \\
\hline
\end{tabular}

Values are Mean $\pm S D, N=6=$ number of animals, ${ }^{* * *} \mathrm{p}<0.00 \mathrm{I}=$ highly significant

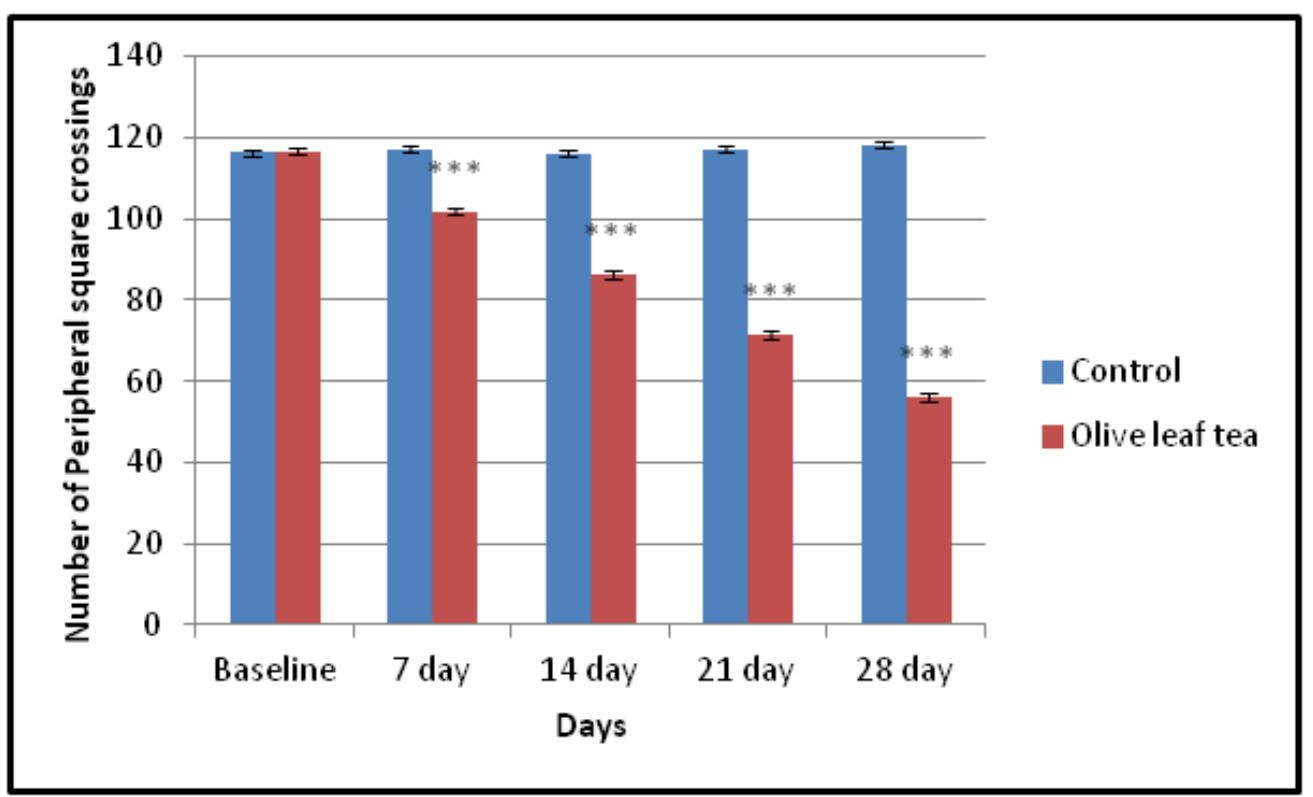

Figure 4 Effect of olive leaf tea on peripheral square crossings.

\section{Conclusion}

From our research study, it can be concluded that olive leaf tea plays a significant role in decreasing anxiety due to presence of Oleuropein which possesses anxiolytic, anti-oxidant as well as other pharmacological activities (anti-inflammatory).These pharmacological activities can also be beneficial for a healthy life style and other aspects of life if a normal individual were to consume olive leaf tea as part of a daily routine.

\section{Acknowledgments}

None

\section{Conflicts of interest}

The author declares that there are no conflicts of interest.

\section{Funding}

None

\section{References}

1. Hill C, Waite P, Creswell C. Anxiety disorders in children and adolescents. Paediatrics and Child Health. 2016;26(12):548-553.

2. Temitope BE. Effect of stress and anxiety on general life satisfaction among working mothers in Ado-Ekiti, Ekiti State Nigeria. American Journal of Psychology and Behavioral Sciences. 2015;2(1):7-13.

3. Kumar M, Mondal A. A study on Internet addiction and its relation to psychopathology and self-esteem among college students. Industrial psychiatry journal. 2018;27(1):61-66.
4. Taylor S. Treating anxiety sensitivity in adults with anxiety and related disorders; in The Clinician's Guide to Anxiety Sensitivity Treatment and Assessment 2019. Academic Press. 2019;55-75.

5. Sarfaraz S, Khatoon H, Moin H, et al. Evaluation of anxiolytic effect of Pineapple Juice. Research and Reviews: Journal of Pharmacy and Pharmaceutical Sciences. 2015;(3):38-45.

6. Lydiard RB. The role of GABA in anxiety disorders. J Clin Psychiatry. 2003;64(3):21-27.

7. Nuss P. Anxiety disorders and GABA neurotransmission: a disturbance of modulation. Neuropsychiatric disease and treatment. 2015;11:165-175.

8. Sana Sarfaraz, Rahila Najam, Abeer Sarfaraz . CNS Depressant, sedative and Anxiolytic activity of ethanolic extract of fruit of Piper chaba revealed after neuropharmacological screening. International Journal of Pharmacy and Pharmaceutical Sciences.2014;6(11):186-189.

9. Pan SY, Zhou SF, Gao SH, et al. New perspectives on how to discover drugs from herbal medicines: CAM's outstanding contribution to modern therapeutics. Evidence-Based Complementary and Alternative Medicine. 2013.

10. Sana Sarfaraz, Tanveer Bano, Ayesha Sabir. Comparative evaluation of Anxiolytic effects of pure lemon juice versus reconstituted lemon drink. World Journal of Pharmacy and Pharmaceutical Sciences. 2015;4(9):1380-1387.

11. Hashmi MA, Khan A, Hanif M, et al. Traditional uses, phytochemistry, and pharmacology of Olea europaea (olive). Evid Based Complement Alternat Med. 2015; 2015:541591.

12. Omar SH. Oleuropein in olive and its pharmacological effects. Sci Pharm. 2010;78(2):133-154. 
13. Somova LI, Shode FO, Ramnanan P, et al. Antihypertensive, antiatherosclerotic and antioxidant activity of triterpenoids isolated from Olea europaea, subspecies africana leaves. J Ethnopharmacol. 2003;84(2-3):299-305.

14. Sabry OM. Beneficial health effects of olive leaves extracts. Journal of Natural Sciences Research. 2014;4(19):1-9.

15. Maurizio Casarrubea, Filippina Sorbera, Andrea Santangelo, et al. Microstructure of rat behavioral response to anxiety in hole-board Neurosci Lett. 2010;481(2):82-87.

16. Casarrubea M, Sorbera F, Crescimanno G. Structure of rat behavior in holeboard: II) multivariate analysis of modifications induced by diazepam. Physiol Behav. 2009;96(4-5):683-692.

17. Porter JH, Prus AJ, Overton DA. Drug discrimination:historical origins, important concepts, and principles. Curr Top Behav Neurosci. 2018;39:326.

18. Carobrez AP, Bertoglio LJ. Ethological and temporal analyses of anxietylike behavior: the elevated plus-maze model 20 years on. Neurosci Biobehav Rev. 2005;29(8):1193-1205.

19. Amany MB, Shaker MA. Olive Leaves Healthy Alternative for Green Tea. Curr Trends Biomedical Eng \& Biosci. 2018;14(3):66-67.

20. Márquez C, Nadal R, Armario A. Influence of reactivity to novelty and anxiety on hypothalamic-pituitary-adrenal and prolactin responses to two different novel environments in adult male rats. Behav Brain Res. 2006;168(1):13-22.

21. Podsevatkin VG, Kiriukhina SV, Podsevatkin DV, et al. Dynamics of the behavioral response and cortisol level caused by the combined action of mexidole, diazepam, thymogen, and hyperbaric oxygenation in mice under immobilization stress conditions. Eksp Klin Farmakol. 2008;71: $22-25$.

22. Hossain MA, Rahman SM. Total phenolics, flavonoids and antioxidant activity of tropical fruit pineapple. Food Research International. 2011;44(3):672-676.

23. Zubair S, Sarfaraz S, Naveed S, et al. Evaluation of Effect of Coconut Milk on Anxiety. J Anal Pharm Res. 2017;6(4):00182.

24. Gautam M, Agrawal M, Gautam M, et al. Role of antioxidants in generalised anxiety disorder and depression. Indian $J$ Psychiatry. 2012;54(3):244-247.
25. Rao TS, Asha MR, Ramesh BN, et al. Understanding nutrition, depression and mental illnesses. Indian J Psychiatry. 2008;50(2):77-82.

26. Andrikopoulos NK, Kaliora AC, Assimopoulou AN, et al. Inhibitory activity of minor polyphenolic and nonpolyphenolic constituents of olive oil against in vitro low-density lipoprotein oxidation. J Med Food. 2002;5(1):1-7.

27. Visioli F, Poli A, Gall C. Antioxidant and other biological activities of phenols from olives and olive oil. Med Res Rev. 2002;22(1):65-75.

28. Bendini A, Cerretani L, Carrasco-Pancorbo A, et al. Phenolic molecules in virgin olive oils: a survey of their sensory properties, health effects, antioxidant activity and analytical methods: an overview of the last decade. Molecules. 2007;12(8):1679-1719.

29. Choleris E, Thomas AW, Kavaliers M, et al. A detailed ethological analysis of the mouse open field test: effects of diazepam, chlordiazepoxide and an extremely low frequency pulsed magnetic field. Neurosci Biobehav Rev. 2001;25(3):235-260.

30. Hånell $\mathrm{A}$, Marklund N. Structured evaluation of rodent behavioral tests used in drug discovery research. Front Behav Neurosci. 2014;8:252.

31. Prut L, Belzung C. The open field as a paradigm to measure the effects of drugs on anxiety-like behaviors: a review. Eur J Pharmacol. 2003;463(13):3-33.

32. Brenes Sáenz JC, Villagra OR, Fornaguera Trías J. Factor analysis of Forced Swimming test, Sucrose Preference test and Open Field test on enriched, social and isolated reared rats. Behav Brain Res. 2006;169(1):57-65.

33. Dekanski D, Selaković V, Piperski V, et al. Protective effect of olive leaf extract on hippocampal injury induced by transient global cerebral ischemia and reperfusion in Mongolian gerbils. Phytomedicine. 2011;18(13):1137-1143.

34. Pourkhodadad S, Alirezaei M, Moghaddasi M, et al. Neuroprotective effects of oleuropein against cognitive dysfunction induced by colchicine in hippocampal CA1 area in rats. J Physiol Sci. 2016;66(5):397-405.

35. Cohen H, Liu T, Kozlovsky N, et al. The neuropeptideY(NPY)-ergic system is associated with behavioral resilience to stress exposure in an animal model of post-traumatic stress disorder. Neuropsychopharmacology. 2012;37(2):350-363. 